\title{
"Exemplary" Exculpatory Agreement Forms Recommended for Use in Exercise and Sport Settings: Are They Effective?
}

\author{
Todd L. Seidler, Ph.D. \\ Guilford College \\ and \\ Bradley J. Cardinal, Ph.D. \\ Wayne State University
}

\section{Introduction}

It has become the accepted standard of practice for facility managers and program directors involved in sport and physical activity to implement a formal program of managing the risks involved. The reasons for this are twofold. First, sport managers have a moral and legal obligation to make their programs as safe as possible for the participants. Secondly, they must protect the assets of the organization from financial liability resulting from claims of negligence. One method of protecting assets that is often used by sport managers is the judicious use of exculpatory agreements such as waivers and releases of liability (van der Smissen, 1990).

While the use of exculpatory agreements are sometimes thought to be worthless for protecting oneself from negligence claims, this is not so. Cotten states (1996, p. 29) "The fact is ... that in at least 45 states, a well written waiver, signed voluntarily by an adult, can serve as a complete bar to liability for injuries caused by the negligence of the business or its employees." Thus, the prudent use of exculpatory agreements should be one aspect of an overall risk management program.

To assess the quality of these forms, a "Waiver Evaluation Checklist" was developed by Cotten (1995). This checklist provides a framework for sport managers to examine the comprehensiveness of the waivers used in their pro- grams. It also may serve as a measure of the quality of existing, exemplary exculpatory agreement forms.

The primary purpose of this study was to determine the extent to which a sample of "exemplary" exculpatory agreement forms met the breadth of content outlined in Cotten's (1995) "Waiver Evaluation Checklist." Ancillary objectives included determining the reliability and objectivity of Cotten's measure.

\section{Method}

\section{Unit of Analysis}

Exemplary exculpatory agreement forms (i.e., contracts in which participants are asked to relinquish their rights to pursue legal action) were obtained through published sources and professional conference attendance $(\underline{N}=22)$. "Exemplary" exculpatory agreements are defined as those that have been published in a professional book or journal or handed out at a professional conference and are presented as examples that have successfully held up in court.

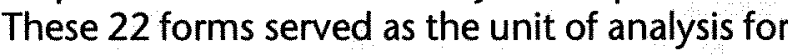
this study.

\section{Measure}

Cotten's (1995) Waiver Evaluation Checklist was applied to each form. When constructing the checklist, Cotten studied the require- 
ments for valid waivers in each state in order to meet the requirements of even the strictest states in which waivers are allowed.

Cotten's (1995) measure contains 20 dichotomous (i.e., yes, no) questions organized around three factors: requirements for a legal contract ( $\underline{n}=7)$, format and exculpatory language $(\underline{n}=7)$, and other protective language within the waiver $(n=6)$. A sample item is "Does the waiver include a statement of disclaimer by the business?" A description and/or example follows each question. For the aforementioned question the description was, "In a disclaimer, the business asserts lack of responsibility or liability for injury resulting from the provision of the service." An assumption of Cotten's measure is that it is valid. That is, an exculpatory agreement form not meeting all 20 criteria may be legally challenged on the basis of the missing criteria or criterion. In the absence of direct litigation to the contrary, this checklist then serves as a measure of effectiveness (i.e., criterion and content validity).

\section{Procedures}

The 22 exemplary exculpatory agreement forms were evaluated using Cotten's (1995) checklist by two independent evaluators. Both evaluators held bachelor's degrees in Sports Administration (University of Windsor, Canada) and were completing master's degrees in Sports Administration (Wayne State University, Detroit) at the time of the study. In addition to their formal education, both were active sports administration professionals.

\section{Data Analysis}

Descriptive statistics $(\underline{M}, \underline{S D}$ percentages) were computed separately for each of the 20 items and for each of the evaluators. KuderRichardson reliability coefficients (KR20) were computed for each evaluator's results to determine intra- rater reliability (Richardson \& Kuder, 1937). The KR-20 coefficient is an estimate of the internal consistency of a measure comprised of dichotomous items. Nunnally's (1978) recommended value of .70 was the criterion against which each evaluator's results were compared. Inter-rater reliability (i.e., a form of objectivity) was determined using percentages of agreement between evaluators and Pearson's correlation coefficients (r) for each item on the checklist. An alpha level of $p<.05$ was used to evaluate each correlation coefficient.

\section{Table 1}

Percentage of forms meeting each of the criteria suggested by Cotten (in press).

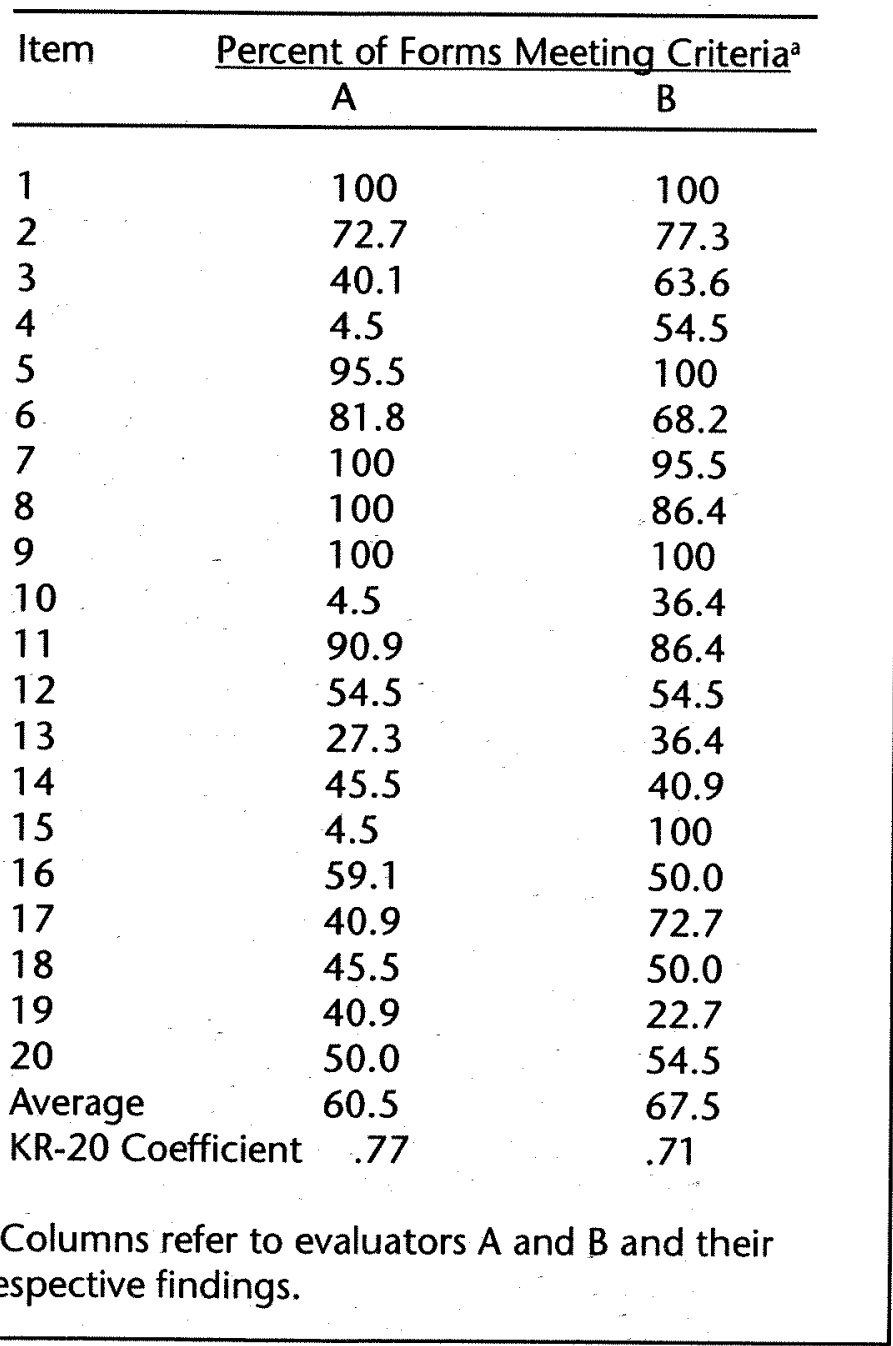




\section{Table 2}

Inter-rater reliability (objectivity).

\begin{tabular}{llll}
\hline Item & \% Agreement & $\mathrm{r}$ & $\mathrm{p}$ \\
\hline 1 & 100 & 1.00 & - \\
2 & 95.4 & .93 & $<.001$ \\
3 & 77.3 & .74 & $<.001$ \\
4 & 100 & 1.00 & - \\
5 & 95.4 & .93 & $<.001$ \\
6 & 72.7 & .64 & $<.001$ \\
7 & 90.9 & .88 & $<.001$ \\
8 & 86.4 & .82 & $<.001$ \\
9 & 100 & 1.00 & - \\
10 & 59.1 & .54 & $<.01$ \\
11 & 95.4 & .93 & $<.001$ \\
12 & 100 & 1.00 & - \\
13 & 77.3 & .72 & $<.001$ \\
14 & 81.8 & .73 & $<.001$ \\
15 & 4.5 & -.93 & $<.001$ \\
16 & 81.8 & .74 & $<.001$ \\
17 & 72.7 & .70 & $<.001$ \\
18 & 81.8 & .73 & $<.001$ \\
19 & 63.6 & .57 & $<.01$ \\
20 & 72.7 & .59 & $<.01$ \\
Overall & 80.5 & .71 & $<.001$ \\
& & & \\
& & &
\end{tabular}

2 presents a summary of the inter-rater reliability scores.

\section{Discussion}

This study determined the extent a sample of 22 exemplary exculpatory agreement forms met the breadth of content outlined in Cotten's (1995) Waiver Evaluation Checklist. Each form's content was assessed by two independent evaluators. Overall, no form met all 20 of Cotten's (1995) criteria. As Cotten's checklist is designed to assess the criterion and content validity of these forms and these forms serve as examples for professional practice, this is noteworthy. According to Cotten, if a form does not meet all 20 of the criterion, it may be legally challenged on the basis of the missing crite$\mathrm{ria} / \mathrm{criterion}$. Developers of these forms should be aware of this finding and are encouraged to assess their own forms using Cotten's checklist.

Only two of the 20 criteria were present in all of the forms according to both evaluators (i.e., questions one and nine). How-

\section{Results}

Table 1 shows the percentage of forms meeting each of the 20 criteria on Cotten's (1995) checklist. Overall, evaluator A and B found the average exemplary exculpatory agreement form met $60.5 \%(\underline{S D}=3.3$; range $=35 \%$ $-95 \%)$ and $67.5 \%(\underline{S D}=3.1$; range $=35 \%$ $95 \%$ ) of the criteria, respectively. No form met all 20 of Cotten's criteria.

Both evaluators demonstrated good intrarater reliability (i.e., KR-20 reliability coefficients of .77 and .71 for evaluator $A$ and $B$, respectively). In terms of inter-rater reliability (i.e., objectivity), $80.5 \%$ agreement was achieved between evaluators overall and the overall correlation coefficient was $\underline{r}=.71(\underline{p}<.0001)$. Table ever, on the basis of an earlier study (Cardinal \& Seidler, 1994), there is reason to question whether the forms did indeed meet the criteria stated in question one (i.e., easily read and understood). In the Cardinal and Seidler study, a sample of 36 participant forms were evaluated for readability. Overall they found that only two forms $(5.6 \%)$ were written at the high school grade level, $61.1 \%$ at the undergraduate reading level, and $33.3 \%$ at or beyond the graduate school reading level. As both evaluator's in this study were nearing completion of their master's degrees in Sports Administration and employeed in the Sports Administration field, it is likely that to them the forms were easily read and understood. How well the average layperson can read and understand these forms remains an impor- 
tant question and developers of exculpatory agreement forms are encouraged to consider applying more objective measures (e.g., readability assessments) when assessing this criterion.

Criterion 15 was the least objective and reliable. However, during a discussion following the study it was apparent that one evaluator had misinterpreted the statement and evaluated each form based on that misinterpretation. After further discussion, it was concluded that both evaluators were really in agreement. To avoid these problems in the future, perhaps this item could be clarified and/or supplemented with additional examples.

An important aspect of any measure is whether or not it can be applied reliably and objectively. Our findings generally support both aspects of the measure using well established, empirical approaches. As a result, we have helped to establish the scientific authenticity of Cotten's (1995) checklist.

A common method used by sport managers when developing exculpatory agreements is to find a form that was used for another program or event and adapt it to their situation. This usually means altering the information specific to their event, (i.e., name, date, location, etc.) exclusively, while leaving the exculpatory language intact. Even worse, if an exculpatory agreement is used in this fashion, it can become a problem in that practitioners may make the assumption that since it has been presented as an exemplary form, it should also be a good, effective waiver or release for their situation. Unfortunately, an exculpatory agreement that is successful in a given situation or state may be worthless in another (Cotten, 1993).

A limitation of this study is that only a small sample of exemplary exculpatory agreement forms were evaluated. Future research using larger and more diverse samples of forms may be of interest. Second, both evaluators were similar in academic preparation and training. Future studies in which persons with different backgrounds are used as evaluators may be of interest. For example, a Sports or Recreation Administration academician, a lawyer, a professional in the field, and a layperson could all evaluate a set of forms. This type of study may reveal a great deal about the utility of the measure and who may accurately apply it. Lastly, the ultimate test of Cotten's (1995) checklist will have to come in the courtroom. If a form meets all of Cotten's criteria and still is not upheld in court, additional criterion may need to be added to the checklist.

It is apparent from this study that most exculpatory agreements that are presented in the professional literature do a poor job of meeting the criteria of Cotten's (1995) checklist. It is important that sport managers be careful when developing exculpatory agreements for use in their programs. It is recommended that, when developing an exculpatory agreement, sport managers use Cotten's checklist as the minimum standard for evaluating such forms. Additionally, sport managers should consult a local attorney who is familiar with the laws associated with such agreements. Even if an attorney is consulted or prepares the form, Cotten's checklist should be used to evaluate the form's appropriateness and completeness.

\section{References}

Cardinal, B. J., \& Seidler, T. L. (1994). Readability of "exemplary" participant forms recommended for use in sport and exercise settings. Lournal of Legal Aspects of Sport, 4(2), 1-6.

Cotten, D. I. (1993). Analysis of the state laws governing the validity of sport-related exculpatory agreements. lournal of Legal Aspects of Sport, 3(2), 50-63.

Cotten, D. J. (1994). Ambiguity as a factor in the validity of exculpatory agreements. Lournal of Legal Aspects of Sport, 4(2), 7-20.

Cotten, D. J. (1995). Waiver evaluation checklist. Paper presented at the North American Society for Sport Management International Conference, Athens, GA.

Cotten, D. J. (1996). Before the fall. Athletic Business, 20(5), 29-37.

Cotten, D. J. (1996). Guidelines for writing or evaluation [sic] exculpatory agreements. Lournal of Legal Aspects of Sport, 6(2), 117-122.

Nunally, J. C. (1978). Psychometric theory. New York: McGraw-Hill.

Richardson, G. F., \& Kuder, M. (1937). The theory of the estimate of test reliability. Psychometrika, 2, 135-138. van der Smissen, B. (1990). Legal liability and risk management for public and private entities. Cincinnati, $\mathrm{OH}$ : Anderson.

\section{See Yaw in Culanda!}

